\title{
Razor blade removal from the stomach utilizing a novel modification of the overtube
}

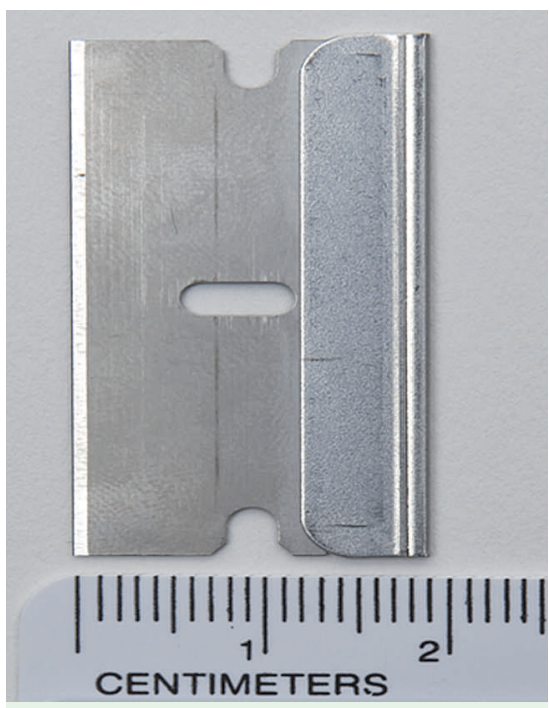

Fig. 1 Dimensions of the single-edge razor blade shown against a scale. Each blade measures $40 \mathrm{~mm}$ in length $\times 18 \mathrm{~mm}$ in height $\times 0.22 \mathrm{~mm}$ in width.

Impacted sharp foreign bodies in the gastrointestinal tract can be very difficult to manage, with different methods described in literature for their safe removal [1 -4]. With the flexible endoscope, a foreign-body protector hood or overtube is generally used to protect the esophagus when removing a sharp foreign body. However, the size of the overtube precludes removal of foreign body more than $16.7 \mathrm{~mm}$ in size. This report illustrates an unusual modification of a commercial overtube in order to facilitate the safe withdrawal of a sharp foreign body that would not otherwise have been possible with the standard equipment available.

A 26-year-old female was admitted to our hospital after swallowing a razor blade. Her past medical history was significant for bipolar disorder and prior exploratory laparoscopy for removal of ingested foreign bodies. The razor blade was visualized in the distal esophagus on esophago-
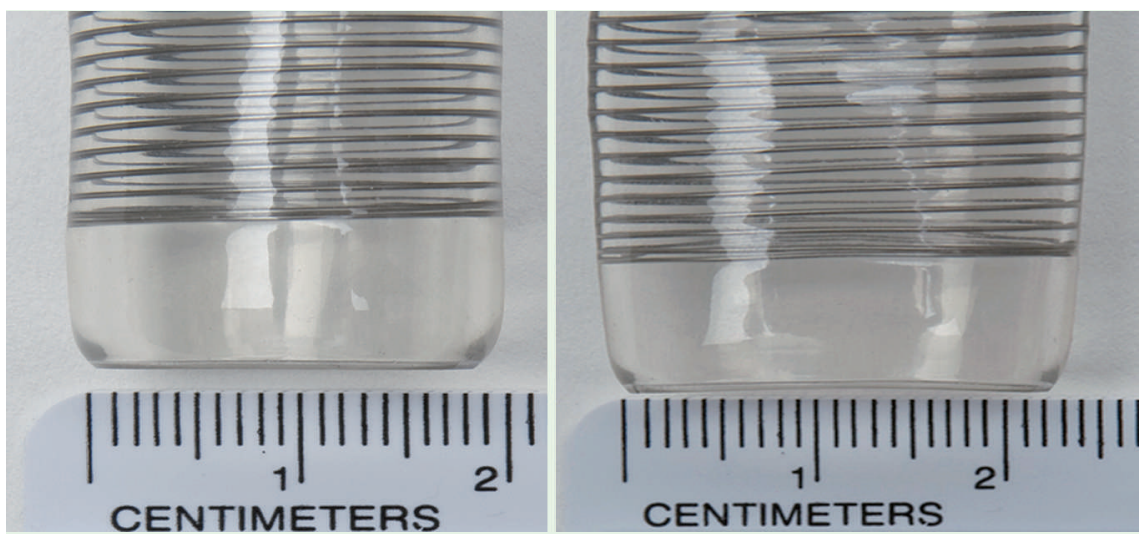

Fig. 2 Maximum diameter of overtube before and after flattening of the distal end.

duodenoscopy and easily grasped, but was larger than the 16.7-mm-internal-diameter tapered end of the US Endoscopy Guardus overtube (US Endoscopy, Mentor, Ohio, USA) ( $\bullet$ Fig. 1).

The patient was taken to the operating room, where a plain film showed that the razor blade had migrated to the stomach. A decision was made to incise the distal 2-mm tapered end of the overtube and to flatten the distal $3 \mathrm{~cm}$ of the overtube to provide a wider oval shape in order to allow the razor blade to be pulled into the overtube ( $\bullet$ Fig. 2 ).

The modified overtube was backloaded over the scope and introduced into the stomach where the razor blade was pulled into the overtube and removed successfully. Re-endoscopy showed no evidence of laceration in the esophagus. This modification of the overtube is safe, effective, and can be easily applied for removal of larger sharp foreign bodies without incurring any additional costs.

Endoscopy_UCTN_Code_TTT_1AO_2AL

\section{Alhaji, A. Atreja, B. R. Upchurch}

Department of Gastroenterology,

Digestive Diseases Institute, Cleveland

Clinic Foundation, Cleveland, Ohio, USA

\section{References}

1 Roffman E, Jalisi S, Hybels $R$, Catalano $P$. Failed extraction of a sharp esophageal foreign body with a flexible endoscope: a case report and review of the literature. Arch Otolaryngol Head Neck Surg 2002; 128: 1096- 1098

2 Dolay K, Soylu A, Oner OZ, Aygun E. Removal of a razor blade from the stomach with unusual accessory tools. Endoscopy 2007; 39 (Suppl 1): E255

3 Bertoni G, Pacchione D, Conigliaro R et al. Endoscopic protector hood for safe removal of sharp-pointed gastroesophageal foreign bodies. Surg Endosc 1992; 6: 255-258

4 Smith MT, Wong RK. Esophageal foreign bodies: types and techniques for removal. Curr Treat Options Gastroenterol 2006; 9: $75-84$

\section{Bibliography}

DOI $10.1055 / \mathrm{s}-0029-1214697$

Endoscopy 2009; 41: E166

(c) Georg Thieme Verlag KG Stuttgart · New York . ISSN 0013-726X

\section{Corresponding author}

\section{A. Atreja, MD, MPH}

Cleveland Clinic

Mail Stop A-30, 9500 Euclid Ave

Cleveland

OH 44195

USA

Fax: +1-216-6361796

atrejaa@ccf.org 